Jurnal Bimbingan dan Konseling Ar-Rahman
Volume 5, Nomor 2, Tahun 2019
Tersedia Online: http://ojs.uniska.ac.id/index.php/BKA
e-ISSN 2477-6300

\title{
KONSELING KELOMPOK TEKNIK ROLE PLAY UNTUK MENINGKATKAN KEPERCAYAAN DIRI PADA SISWA KELAS VIIB SMP NEGERI 31 BANJARMASIN
}

\author{
Purnama Sari, Sultani, Laelatul Anisah \\ Program Studi Bimbingan dan Konseling, Fakultas Keguruan dan Ilmu Pendidikan, Universitas Islam \\ Kalimantan Muhammad Arsyad Al Banjari, Banjarmasin \\ saripurnama556@gmail.com
}

\begin{abstract}
ABSTRAK
Penelitian ini dilatar belakangi kerena siswa yang kurang memiliki kepercayaan diri akan kemampuan yang dimilikinya. Orang yang kurang percaya diri bisanya sering menutup diri, memilih untuk diam karena takut diejek oleh orang lain.Tujuan penelitian untuk mengetahui tingkat kepercayaan diri sebelum dilaksanakan konseling kelompok dengan teknik Role Play, untuk mengetahui tingkat kepercayaan diri sesudah dilaksanakan konseling kelompok dengan teknik Role Play dan untuk mengetahui apakah kepercayaan diri dapat ditingkatkan melalui konseling kelompok dengan teknik Role Play pada siswa. Penelitian menggunakan pre-eksperimental design yaitu one-group pretest dan posttest design. Prosedur penelitian pretest-treatment-posttest. Teknik pengambilan sampel menggunakan purposive sampling. Sampel 8 responden dari 30 populasi. Teknik pengumpulan data menggunakan skala pengukuran melalui angket. Validitas angket menggunakan Pearson Correlation dan reliabilitas menggunakan alpha cronbach. Teknik analisis data menggunakan hitungan statistik deskriptif, dan uji wilcoxon dengan aplikasi IBM SPSS Statistik 25. Hasil pretest siswa ditemukan 8 siswa dengan skor terendah. Hasil posttest siswa ada peningkatan skor dari 8 siswa. Perhitungan uji wilcoxon pada data keseluruhan diperoleh nilai signifikansi (Sig). Sebesar 0,005 kurang dari 0,05. Hal ini berarti ada pengaruh konseling kelompok dengan teknik Role Play. Saran, Bagi guru BK agar menerapkan konseling kelompok dengan teknik roly play. Bagi siswa agar meningkatkan kepercayaan diri dalam kehidupan sehari-hari. Bagi peneliti selanjutnya agar menggunakan waktu sebaik-baiknya.
\end{abstract}

Kata Kunci: Konseling Kelompok, Role Play, Kepercayaan Diri

\section{ABSTRACT}

This research is motivated because studenst who lack confidence in their abilities. Confident people usually shut down, choosing to be quiet for fear of being ridiculed by others. The purpose of this research is to determine the level of confidence before group counseling with Role Play technique is carried out, to find out the level of confidence after group counseling with Role Play technique and to determine whether confidence can be increased through group counseling with Role Play technique for students. The study used a pre-experimental design namely one-group pretest and posttest design. Pretest-treatment-posttest research procedure. The sampling technique uses purposive sampling. Sample 8 respondents from 30 populations. Data collection techniques using a measurement scale through a questionnaire. The validity of the questionnaire using Pearson Correlation and reliability using alpha cronbach. Data analysis techniques using descriptive statistical calculations, and Wilcoxon test with the application of IBM SPSS Statistics 25.Student pretest results found 8 students with the lowest score. The students' posttest results increased scores from 8 students. Wilcoxon test calculations on the overall data obtained significance value (Sig). For 0.005 is less than 0.05. This means that there is an influence of group counseling with the Role Play technique. Suggestion, for BK teachers to apply group counseling with the roly play technique. For students to increase self-confidence in daily life. For future researchers to make the best use of time.

Keywords: Group Counseling, Role Play, Confidence 
Purnama Sari, Sultani, Laelatul Anisah

Jurnal Bimbingan dan Konseling Ar-Rahman

Volume 5, Nomor 2, Tahun 2019

e-ISSN 2477-6300

\section{PENDAHULUAN}

Banyak dikalangan remaja saat ini yang kurang memiliki rasa percaya diri padahal kepercayaan diri merupakan salah satu aspek kepribadian manusia yang berfungsi penting untuk mengaktualisasikan potensi yang dimiliki. Siswa yang tidak percaya diri menurut Sarastika (2014:77) biasanya takut untuk melakukan komunikasi, orang yang kurang percaya diri candrung menutup diri karena takut disalahkan dan diejek oleh orang lain. Selain itu siswa cendrung kurang mampu atau merasa kesulitan dalam menyelesaikan tugas sehingga bisa berpenaruh terhadap nilai akademis. Biasanya gejalagejala itu timbul pada saat siswa melakukan sesuatu yang penting dan penuh tantangan.

Percaya diri menurut Rahayuningdyah (2016) adalah sebagian cara pandang seseorang atau gambaran pemikiran dan perasaan keyakinan, kesanggupanmaupun keberanian seseorang terhadap segenap aspek kemampuan yang dimilikinya. Anak yang percaya diri menurut William James (dalam Herwanto 2018) adalah mampu berinteraksi dalam lingkungan, memiliki tanggung jawab, dan berani bertanya dan menyampaikan pendapat.

Berdasarkan penelitian Rahayuningdyah (2016), keberanian siswa mencapai masalah pribadi dengan jujur meningkat $25.6 \%$, keberanian siswa menyampaikan penyebab rasa malu terhadapat teman meningkat 12.5, memahami masalah yang disampaikan anggota meningkat 20\%, empati meningkat $1.17 \%$. Sehingga dapat dikatakan bahwa layanan konseling kelompok berhasil meningkatkan kepercayaan diri siswa kelas VIIID SMP Negeri 3 Ngrambe tahun ajaran 2014/2015.

Maka dari itu peneliti tertarik melakukan penelitian dengan judul "Layanan konseling kelompok dengan teknik role play untuk meningkatkan kepercayaan diri siswa kelas VII B SMP Negeri 31 Banjamasin. Tujuan dari adanya penelitian ini untuk mengetahui tingkat kepercayaan diri siswa kelas VII B sebelum diberikan layanan konseling kelompok dengan teknik role play, untuk mengetahui tingkat kepercayaan diri siswa kelas VII B sesudah diberikan layanan konseling kelompok dengan teknik role play, dan untuk mengetahui keefektifan layanan konseling kelompok dengan teknik role play dalam meningkatkan kepercayaan diri siswa kelas VII B di SMP negeri 31 Banjarmasin.

\section{METODE}

Metode penelitian yang digunakan dalam penelitian ini adalah Kuntitatif dengan desain menggunakan pre- experimental designs atau eksperimen, metode ini tidak memiliki kelompok control dan sampel yang digunakan peneliti tidak dipilih secara random. Bentuk designs yang digunakan adalah One-Group Pretest-Posttest Design.

Alasan peneliti menggunakan desain ini adalah untuk membandingkan keadaan sample sebelum diberikan treatment dan sesudah diberikan treatment membandingkan keadaan sample peneliti berikan. Mula-mula subjek diberikan Pretest kemudian diberikan treatment dengan beberapa kali lalu kemudian dilakukan kembali pengukuran post-test untuk berbandingan sebelum diberikan treatment dan setelah diberikan treatment.

Populasi dalam penelitian ini dengan seluruh siswa kelas VII B di SMP Negeri 31 Banjarmasin sebanyak 30 respnden dan yang menjadi sampel sebanyak 8 responden sampel penenelitian diambil secara purposive sampling yang artinya mengambil sampel dari populasi yang digunakan disesuaikan dengan kretiria-kriteria tertentu yang diterapkan berdasarkan tujuan peneliti. Alat ukur yang digunakan untuk mengukur kepercayaan diri pada siswa yaitu dengan Skala Likert dengan jumlah angket pertanyaan sebnyak 60 item.

\section{HASIL DAN PEMBAHASAN}

Pendiskripsian hasil penelitian ssebelum dan setelah mendaptkan layanan konseling kelompok dengan teknik role play ini dijelaskan dalam bentuk tabel dan grafik adapun sebagai berikut:

Tabel 1. Kepercayaan Diri Siswa Sebelum (Pretest) dan Sesudah (Posttest)

\begin{tabular}{ccccc}
\hline Nama & Pretest & Kategori & Posttest & Kategori \\
\hline AH & 99 & Rendah & 153 & Tinggi \\
AL & 77 & Rendah & 106 & Sedang \\
AD & 96 & Rendah & 110 & Sedang \\
PT & 91 & Rendah & 127 & Sedang \\
HK & 88 & Rendah & 125 & Sedang \\
ND & 94 & Rendah & 130 & Sedang \\
RN & 95 & Rendah & 132 & Sedang \\
ZK & 98 & Rendah & 150 & Tinggi \\
\hline Jumlah & $\mathbf{7 3 8}$ & & $\mathbf{1 , 0 3 3}$ & \\
\hline
\end{tabular}


Purnama Sari, Sultani, Laelatul Anisah

Jurnal Bimbingan dan Konseling Ar-Rahman

Volume 5, Nomor 2, Tahun 2019

e-ISSN 2477-6300

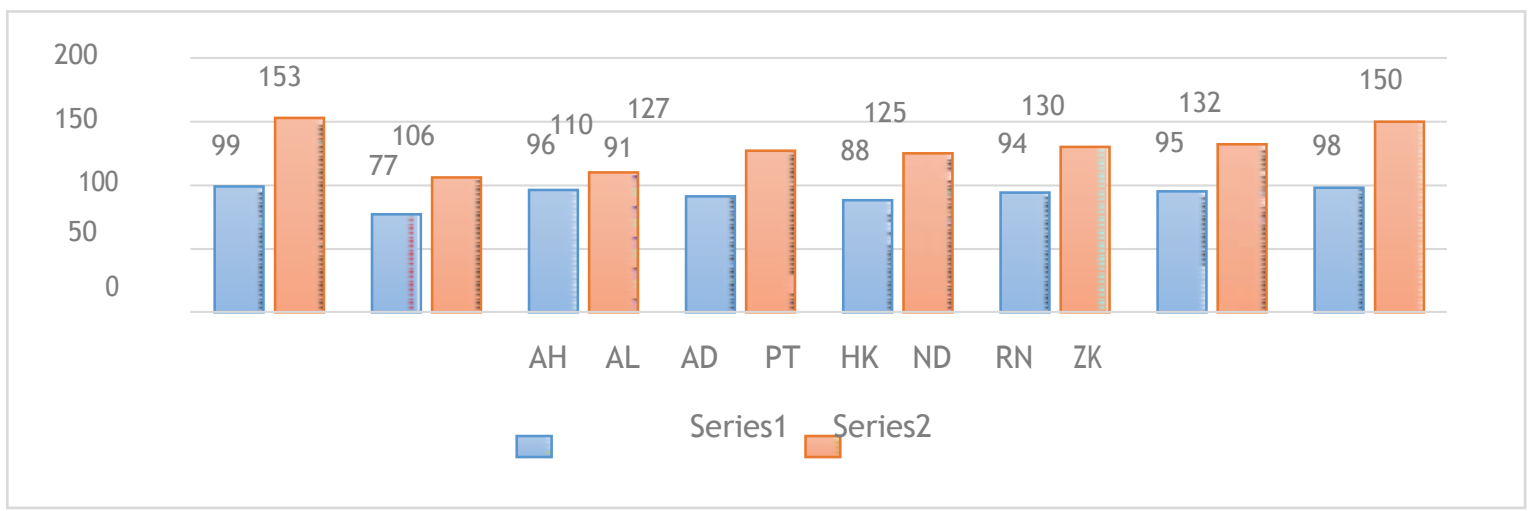

Gambar 1. Grafik Pretest dan Posttest

Berdasarkan hasil dari pretest dan posttest maka dapat disimpulkan layanan konseling kelompok dengan teknik role play efektif untuk meningkatkan kepercayaan diri siswa. Untuk melihat statistik lihat signifakansi, jika nilai sig $<0,05$ hubungan nila Ztabel untuk nilai $-2.527=0.012$

Tabel 2. Hasil Uji Wilcoxon

\begin{tabular}{cc}
\hline & Sesudah-Sebelum \\
\hline$Z$ & $-2.527^{\mathrm{b}}$ \\
$\begin{array}{c}\text { Asymp. Sig. (2- } \\
\text { tailed) }\end{array}$ & 0.012 \\
\hline a. $\quad$ Wilcoxon Signed Ranks Test \\
b. $\quad$ Based on positive ranks.
\end{tabular}

Untuk melihat hasil statistik lihat signifikasi, jika nilai sig $<0,05$ maka berhubungan Nilai $Z_{\text {tabel }}$ untuk nilai $-2.527=0.012$. Berdasarkan hasil penghitungan uji Wilcoxon menggunakan SPSS versi 25 maka diperoleh $Z_{\text {tabel }}$ untuk nilai sig 0,012 jadi $Z_{\text {hitung }}$ sebesar -2.527 karena nilai ini mutlak sehingga tanda negatif tidak diperh itungkan. Sehingga nilai Zhitung menjadi 2.527, selanjutnya nlai Zhitung ini dibandingkan dengan nilai $\mathrm{Z}_{\text {tabel }}$ harga $\mathrm{Z}_{\text {tabel }}=0$. Maka $Z_{\text {hitung }}=2.527>Z_{\text {tabel }}=0$, dalam hal ini $Z_{\text {hitung }}$ sebesar 2.527 dan $Z_{\text {tabel }}$ sebesar 0.012. Dengan demikian, maka Ha diterima dan Ho ditolak. Jadi dapat disimpulkan bahwa penggunaan konseling kelompok dengan teknik role play dapat meningkatkan kepercayaan diri pada siswa kelas VII B di SMP Negeri 31 Banjrmasin.

\section{PENUTUP}

Berdasarkan hasil penelitian dan pembahasan tetang Layanan Konseling Kelompok Dengan Teknik Role Play Untuk Meningkatkan Kepercayaan Diri Pada Siswa Kelas VIIB SMP Negeri 31 Banajrmasin.
Dapat disimpulakan sebelum diberikan treatment kepercayaan diri siswa berada dalam katagori rendah dan setelah diberi treatment berada dalam katagori tinggi.

Saran dari peneliti mengenai hasil dari penelitian maka guru BK dapat menerapkan kembali pelaksaan konseling kelompok kepada siswa yang memiliki kepercayaan diri rendah karena sudah terbukti keefekif untuk meningkatkan kepercaayaan diri siswa. Diharapkan bagi siswa agar dapat menerapkan atau mau mengikuti konseling kelomok dengan teknik role play karena mampu merubah kepercayaan diri siswa yang dalam katagori rendah menjadi tinggi. Peneliti hanya sebatas menguji pengaruh layanan konseling kelompok dengan teknik role play untuk meningkatkan kepercayaan diri siswa saja. Oleh karena itu untuk peneliti selanjutnya dapat mengelola kondisi agar tidak jenuh sehingga lebih efeektif dalam kegiatan konseling.

\section{REFERENSI}

Folastri, S. (2016) Prosuder Layanan Bimbingan dan Bimbingan dan Konseling Kelompok (Panduan Praktis Menyeluruh). Bandung: Mujadih Press

Herwanto R. (2018). Pengaruh Layanan Bimbingan Konseling Dengan Teknik Psikodrama Untuk Meningkatkan Kepercayaan Diri Pada Siswa Kelas VIII di SMP Negeri 4 Bandar Lampung. Skripsi, UIN Raden Intan Lampung.

Lubis, N.L., \& Hasnida. (2016). Konseling Kelompok. Jakarta : Kencana

Rahayuningdyah, E. (2016). Upaya Meningkatkan Kepercayaan Diri Melalui Layanan Konseling Pada Siswa Kelas VIII Di SMP Negeri 3 Ngrambe. Jurnal Ilmiah Peendekatan Eksakta, 1(2), 1-14.

Sarastika, P. (2014). Buku Pintar Tampil Percaya Diri. Yogyakarta : ARAS. 